\title{
Primary Malignant Lymphoma of the Brain in Childhood
}

\author{
-Case Report-
}

\author{
Yutaka KAI, Jun-ichi KURATSU, and Yukitaka USHIO \\ Department of Neurosurgery, Kumamoto University Medical School, Kumamoto
}

\begin{abstract}
A 5-year-old boy presented with a 1-year history of frontal headache and nausea. Neurological examination showed left abducens nerve palsy, left facial nerve palsy, Bruns' nystagmus, and wide-based gait. Neuroimaging demonstrated a lesion with moderate linear enhancement in the left cerebellar hemisphere. He underwent stereotactic needle biopsy. The histological diagnosis was well-differentiated small lymphocytic type of malignant lymphoma. Following the biopsy, the patient underwent radiotherapy (whole brain $30 \mathrm{~Gy}$, local $20 \mathrm{~Gy}$ ). He has been in good condition for more than 5 years. The long-term survival is attributable to the absence of aggressiveness and the good response to radiation of this subtype of malignant lymphoma.
\end{abstract}

Key words: brain, childhood, malignant lymphoma

\section{Introduction}

Primary malignant lymphoma of the brain is responsible for $0.8 \%$ to $2 \%$ of all primary intracranial tumors. ${ }^{12,18]}$ The incidence of malignant lymphoma of the brain has apparently increased in immunocompromised and non-immunocompromised patients. ${ }^{17,20)}$ The majority of patients with primary malignant lymphoma of the brain are adults. The incidence of malignant lymphoma of the brain peaks in patients aged $50-60$ years. ${ }^{11.12,16)}$ Primary malignant lymphoma of the brain in children is rare, accounting for $1.2 \%$ and $1.5 \%$ in large series of pediatric tumors. ${ }^{8,11}$ The prognosis of malignant lymphoma of the brain in children is very poor. ${ }^{13)}$

We treated a 15 -year-old boy with primary malignant lymphoma of the brain who continued to be in good condition more than 5 years after diagnosis and treatment, and discuss the characteristics of primary malignant lymphoma of the brain in childhood.

\section{Case Report}

A 5-year-old boy with a 1-year history of frontal headache and nausea was admitted to our hospital in March 1991. Physical examination revealed no ab-

Received January 24, 1997; Accepted February 3, 1998 normalities, including the lymph nodes. Neurological examination showed left abducens nerve palsy, left facial nerve palsy, Bruns' nystagmus, and widebased gait. Computed tomography (CT) revealed a low density area in the left cerebellar hemisphere which was moderately linearly enhanced after intravenous administration of the contrast medium (Fig. 1). Magnetic resonance imaging demonstrated

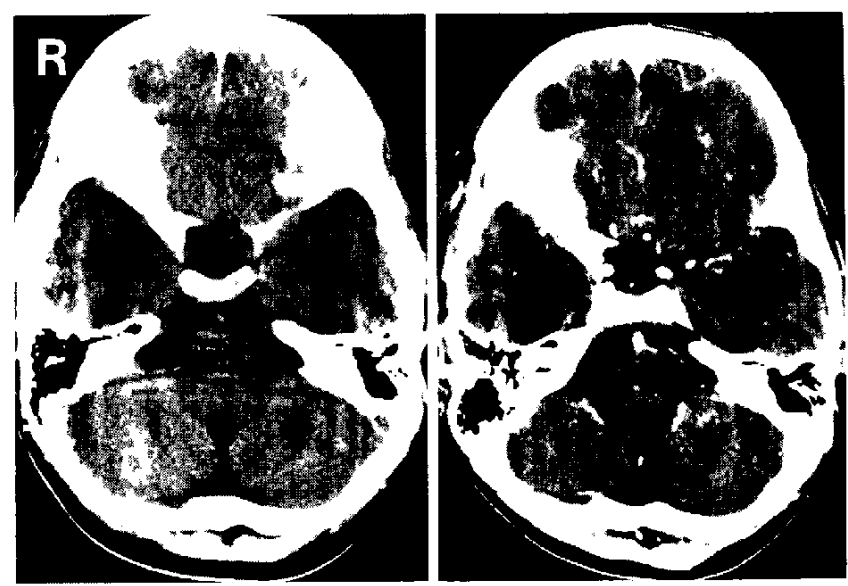

Fig. 1 Computed tomography scans showing a low density area in the left cerebellar hemisphere (left) with moderate linear enhancement after administration of contrast medium (right). 


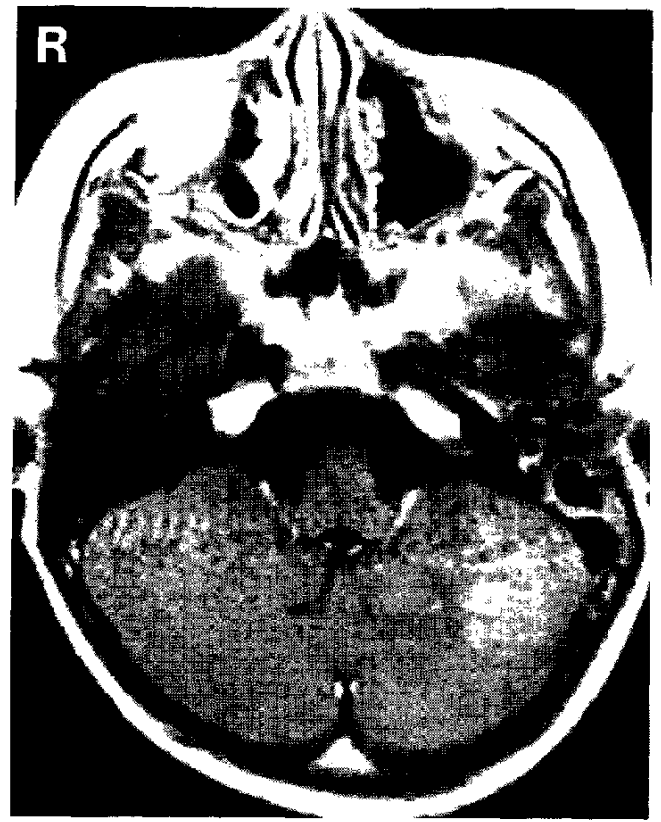

Fig. 2 Axial $\mathrm{T}_{1}$-weighted magnetic resonance image with gadolinium showing the lesion is linearly enhanced.

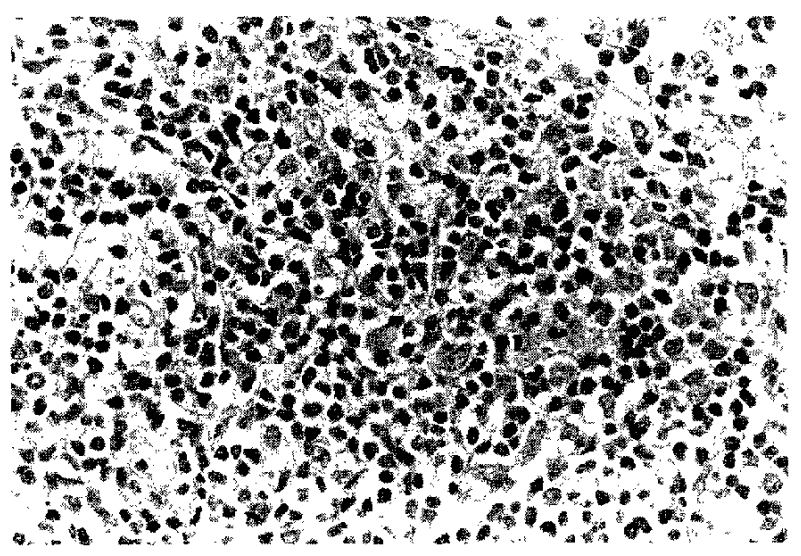

Fig. 3 Photomicrograph showing a malignant lymphoma of the small lymphocytic subtype. The neoplastic cells are small with round nuclei and ill-defined cytoplasm. HE stain, $\times \mathbf{4 0 0}$.

the lesion as low intensity on $\mathrm{T}_{1}$-weighted images and high intensity on $\mathrm{T}_{2}$-weighted images, with linear enhancement after the administration of gadolinium-diethylenetriaminepenta-acetic acid (Fig. 2). He underwent stereotactic needle biopsy of the lesion.

Histological examination showed the tumor was composed of atypical small lymphoid cells. The histological diagnosis was malignant lymphoma of

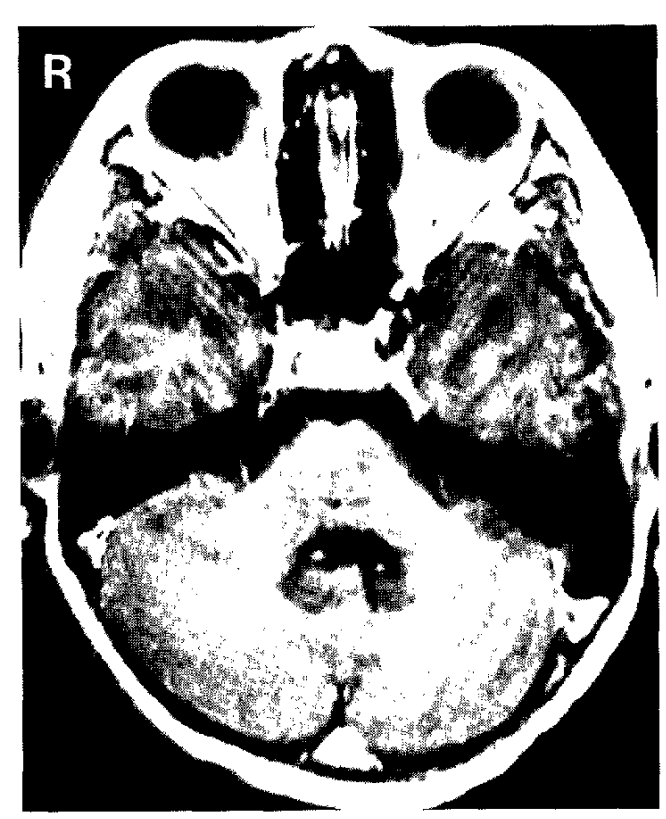

Fig. 4 Axial $\mathrm{T}_{1}$-weighted magnetic resonance image with gadolinium 5 years after treatment showing no recurrence of the tumor.

the small lymphocytic subtype (Fig. 3). Immunohistological staining showed the tumor cells were positive for anti-immunoglobulin $\mathrm{G}$ antibody, suggesting the B cell type.

Blood tests showed his immunological state was normal. Bone marrow analysis was normal. CT and gallium scintigraphy detected no abnormality outside the cerebellum. Following the biopsy, the patient underwent radiotherapy (whole brain $30 \mathrm{~Gy}$, local $20 \mathrm{~Gy}$ ). Two months after the radiotherapy, the tumor had completely disappeared and neurological examination found only mild nystagmus. Five years after diagnosis and treatment, he continued to be in good condition without tumor recurrence (Fig. 4). No mental or somatopsychic deterioration was evident. He is now enjoying school uneventfully with a Karnofsky performance status score of 100.

\section{Discussion}

Primary malignant lymphoma of the brain in children is rare. The Brain Tumor Registry of Japan (1969-1990) contains only nine pediatric cases $(1.5 \%)$ among 596 cases of primary malignant lymphoma of the brain. ${ }^{6)}$ We have treated 36 patients with primary malignant lymphoma of the brain, but only one (the present patient) in a child. ${ }^{16)}$ Only 32 pediatric cases $(18$ males, 13 females, and 1 unknown) of malignant lymphoma in the brain have been reported (including the present 


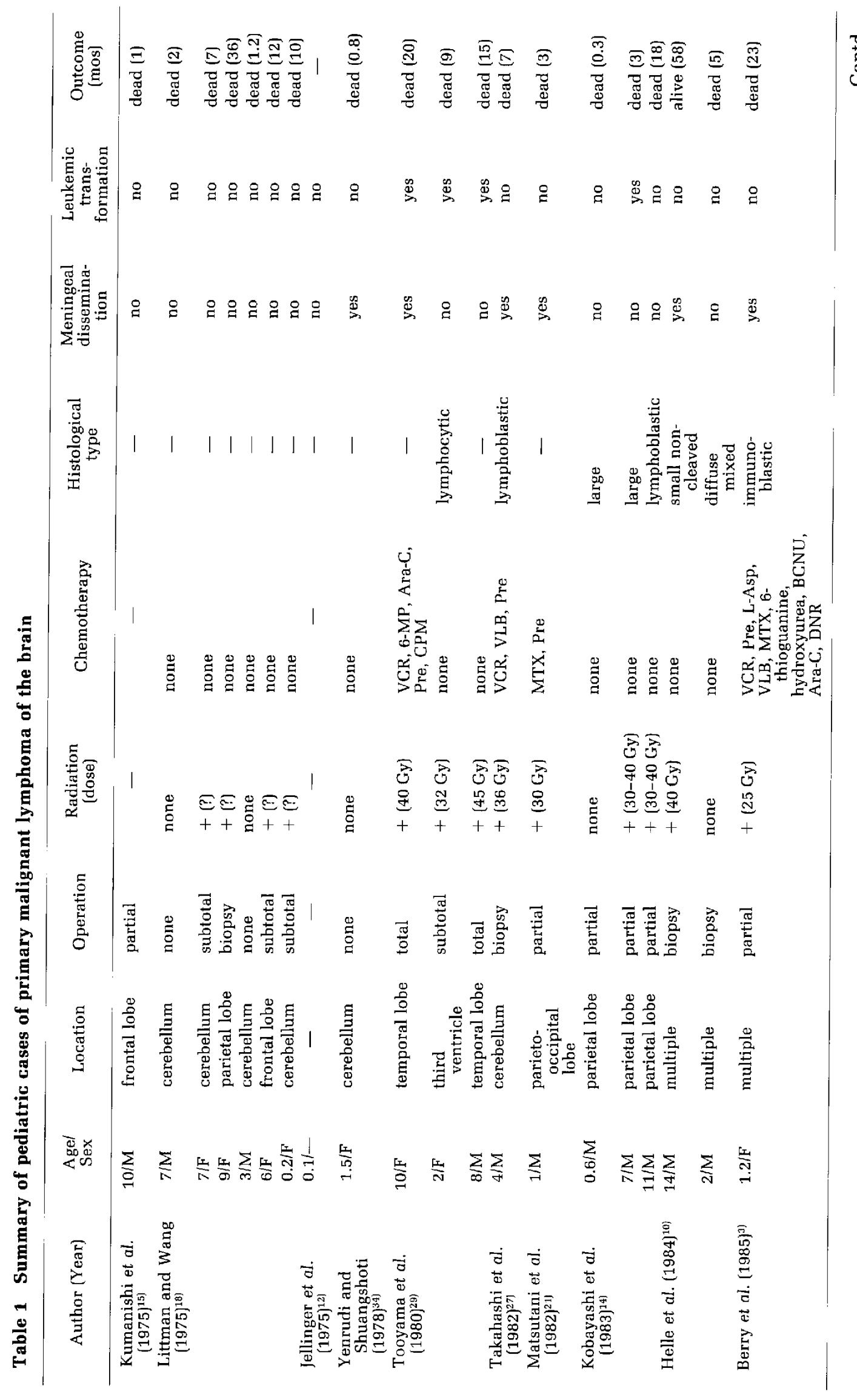




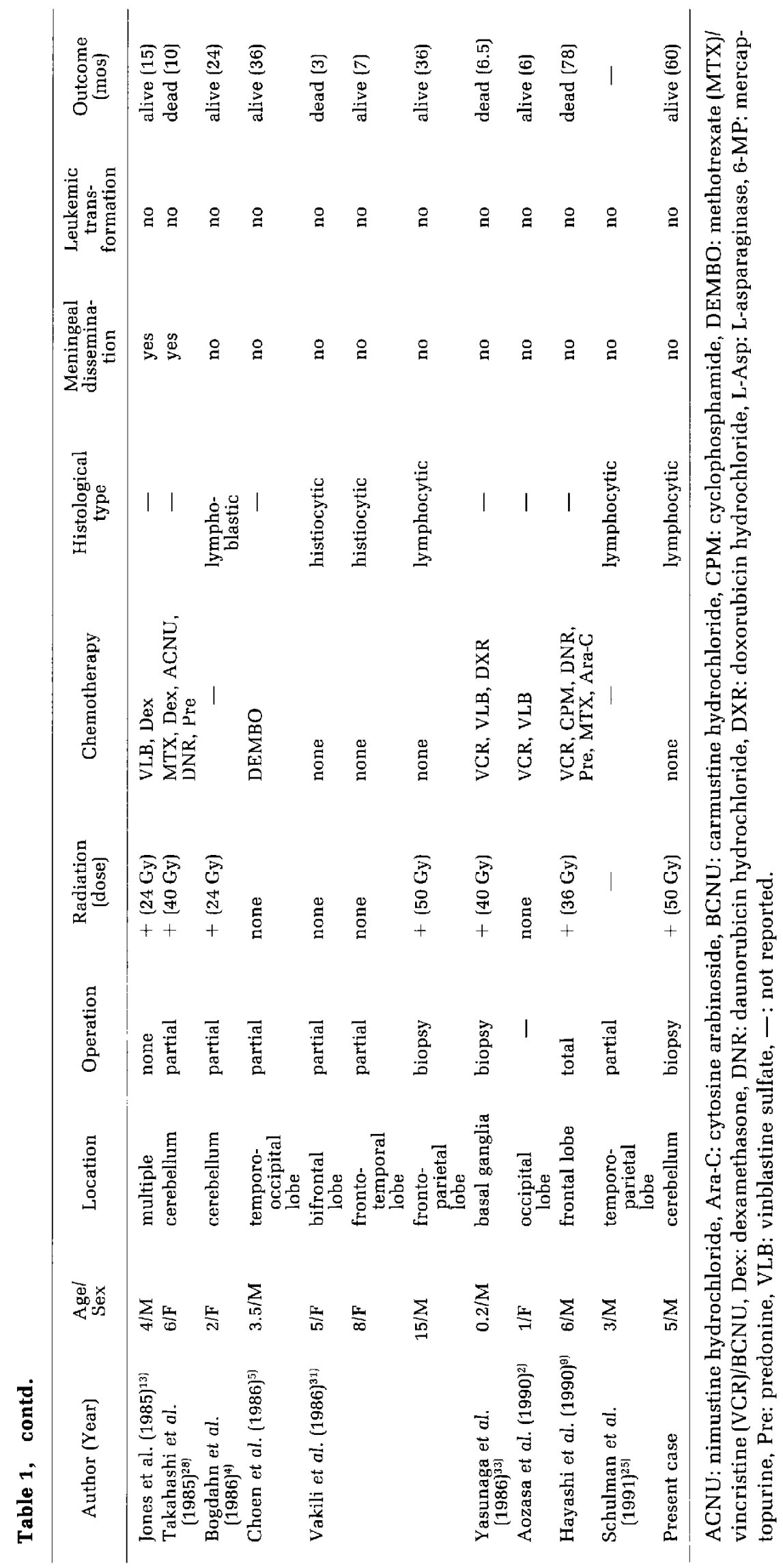


case). $^{2-5,9,10,12-15,18,21,25,27-29,31,33,34)}$ The mean age was 5.1 years, ranging from 0.1 to 15 years (Table 1 ).

Primary malignant lymphoma of the brain in children differs significantly from that in adults. The posterior fossa seems to be the predominant location in children (11/31 patients, $35.5 \%$ ), whereas only $9 \%$ to $11 \%$ are located in the posterior fossa in adults, and the supratentorial region is the predominant site. $^{8)}$

Pediatric cases occasionally have an unusual radiological pattern of irregular enhanced mass with severe edema, or no evidence of an intracranial mass. Meningeal dissemination occurs frequently in pediatric cases $(8 / 32,25.0 \%)$ compared to $6 \%$ in adult cases. ${ }^{8)}$ The characteristic CT features of malignant lymphoma in children are a non-homogeneous pattern, marked edema and prominent mass effect, and especially the "ring-like" peripheral pattern of enhancement. ${ }^{25)}$ One child with primary malignant lymphoma of the brain had no radiological evidence of nodular involvement. ${ }^{13)}$ The CT findings in our patient wеге hypodensity and linear irregular enhancement after contrast medium administration in contrast to findings in adults.

The histological classification of the present case was the small lymphocytic type of B cell type tumor. The histological pattern of malignant lymphoma of the brain seems to depend on the age of the patient. The lymphoblastic type occurs most frequently in children, followed by the null-cell type. The diffuse, large cell type occurs most frequently in adults, and all are $B$ cell type..$^{8,10,17]}$

The prognosis for primary malignant lymphoma of the brain is very poor. Most patients die within a year of diagnosis and the mean survival is about 944.5 months. ${ }^{11,18,33)}$ The prognosis in children seems to be poorer than in adults. The survival for all reported pediatric cases was $0.3-78$ months, and the mean survival time was 17.1 months (Table 1). The prognosis for patients with primary malignant lymphoma of the brain may depend on the histological subtype. ${ }^{10,22)}$ However, there may be no correlation between histological findings and prognosis.,24) Patients with the lymphoblastic type, which seems to predominate in pediatric cases, have a much poorer prognosis because of a high recurrence rate and a tendency to leukemic transformation. ${ }^{12)}$ Leukemic transformation was observed in four of the previously reported pediatric cases. ${ }^{14.29)}$ Our patient had the small lymphocytic type, which has a low recurrence rate and a high sensitivity for radiotherapy. Radiotherapy without subsequent chemotherapy is effective for the treatment of small lymphocytic lymphoma.

Our patient was doing well more than 5 years after the biopsy and radiotherapy. Thirty patients with primary malignant lymphoma of the brain have survived more than 5 years, ${ }^{1,5,18-20,23,30,32)}$ but only one was a child. ${ }^{9)}$ Chemotherapy and/or radiotherapy have yielded good results in two children with primary malignant lymphoma of the brain. ${ }^{5,9)}$ These two patients were alive at 36 and 78 months, respectively. Our patient did not receive chemotherapy. His long-term survival is probably attributable to the absence of aggressiveness and the good response to radiation of the well-differentiated small lymphocytic type of malignant lymphoma.

\section{References}

1) Abelson HT, Kufe DW, Skarin AT: Treatment of central nervous system tumors with methotrexate. Cancer Treat Rep 65: 137-140, 1981

2) Aozasa K, Ohsawa M, Yamabe $\mathrm{H}$ : Malignant lymphoma of the central nervous system in Japan: histologic and immunohistologic studies. Int I Cancer 45: 632636,1990

3) Berry DH, Glaster ES, Jimerez JF, Grunow WA, Jordan R: Primary intracranial immunoblastic lymphoma in infancy. Am J Pediatr Hematol Oncol 7: 141-147, 1985

4) Bogdahn U, Bogdahn S, Mertens HG, Dommasch D, Wodarz R, Wunsch PH, Kuhl P, Richter E: Primary non-Hodgkin's lymphomas of the CNS. Acta Neurol Scand 73: 602-614, 1986

5] Choen IJ, Vogel R, Matz S, Weitz R, Mor C, Stern S, Zairov R: Successful non-neurotoxic therapy (without radiation) of a multifocal primary brain lymphoma with a methotrexate, vincristine, and BCNU protocol (DEMOB). Cancer 57: 6-11, 1986

6) The Committee of Brain Tumor in Japan: Brain Tumor Registry of Japan, vol 9 (1969-1990). 1996, $198 \mathrm{pp}$

7) Grote TH, Grosh WW, List AF, Wiley R, Cousar JB, Johnson DH: Primary lymphoma of the central nervous system. A report of 20 cases and a review of the literature. Am J Clin Oncol 12: 93-100, 1989

8) Hayakawa T, Hiraga S, Aozasa K: CNS-lymphoma Study Group, Japan: New Lecture 4. Tokyo, Shinohara Publication, 1994, pp 4-64

9) Hayashi A, Kyuma Y, Kuwabara T, Fujitsu K, Shinonaga M, Yamaguchi K, Sekido K, Chiba Y, Yamashita T, Oda M, Kuwana N, Fujino H: [Management results of primary intracranial malignant lymphoma]. No Shinkei Geka 18: 715-720, 1990 [Jpn, with Eng abstract)

10) Helle TL, Brill RA, Colby TV: Primary lymphoma of the central nervous system. Clinicopathological study of experience at Stanford. J Neurosurg 60: 94103,1984

11) Henry JM, Heffiner RR Jr, Dillard SH, Earle KM, Davis RL: Primary lymphoma of the central nervous system. Cancer 34: 1293-1302, 1974

12) Jellinger $K$, Randaskiewcz $T$, Slowik F: Primary 
malignant lymphomas of central nervous system in man. Acta Neuropathol Suppl (Berl) 6: 95-102, 1975

13) Jones GR, Mason WH, Fishman LS, Declrck YA: Primary central nervous system lymphoma without intracranial mass in a child. Cancer 56: 2804-2808, 1985

14) Kobayashi T, Shibuya N, Yoshida J, Kageyama N, Usui K, Hara M, Hirota T, Suchi T: [Primary intracranial malignant lymphoma: Clinical and pathoimmunological study]. No Shinkei Geka 11: 917-924, 1983 (Jpn, with Eng abstract)

15) Kumanishi T, Koga M, Ogawa H, Nakamura N, Ikuta F, Oyake Y, Ueki K: [Malignant lymphoma in the central nervous system]. No To Shinkei 27: 21-34, 1975 (Jpn, with Eng abstract)

16) Kuratsu J, Ushio Y: Epidemiological study of primary intracranial tumors: a regional survey in Kumamoto Prefecture in the southern part of Japan. J Neurosurg 84: 946-950, 1996

17) Letendre L, Banks PM, Fresse DS, Miller RH, Scanlon PW, Kiely JM: Primary lymphoma of the central nervous system. Cancer 49: 939-943, 1982

18) Littman P, Wang CC: Reticulum cell sarcoma of the brain. A review of the literature and study of 19 cases. Cancer 35: 1412-1420, 1975

19) Loeffer JS, Ervin TJ, Mauch P, Skarin A, Weinstein HJ, Canellos G, Cassady JR: Primary lymphomas of the central nervous system: Patterns of failure and factors that influence survival. J Clin Oncol 3: 490494, 1985

20) Mackintosh FR, Thomas VC, William JP: Central nervous system involvement in non-Hodgkin's lymphoma. An analysis of 105 cases. Cancer 49: 586-595, 1982

21) Matsutani M, Ohmori H, Terao H, Okeda R, Sekiguchi $\mathrm{T}$ : [A case of primary intracranial malignant lymphoma of an infant with immunodeficiency]. Shoni No Noshinkei 7: 31-36, 1982 (Jpn, with Eng abstract)

22) Perez-Soler R, Smith TL, Cabanillas F: Central nervous system prophylaxis with combined intravenous and intrathecal methotrexate in diffuse lymphoma of aggressive histologic type. Cancer 57: 971-977, 1986

23) Petursson SR: Primary central nervous system lymphoma: Long-term survival following treatment with radiation and methotrexate. Eur J Surg Oncol 15: 6972,1989

24) Pollack IF, Lunsford LD, Flickinger JC, Damoshek HL: Prognostic factors in the diagnosis and treatment of primary central nervous system lymphoma.
Cancer 63: 939-947, 1989

25) Schulman H, Hertzanu Y, Maor E, Hadar A: Primary lymphoma of brain in childhood. Pediatr Radiol 21: 434-435, 1991

26) Soucek D, Ransmayr G, Twerdy K, Zwierzina H, Greil R, Fritsch E, Maier H, Pallua A, Gerstenbrand F: Extensive meningeal involvement as the primary manifestation of a systemic small lymphocytic lymphoma: favourable outcome after irradiation without chemotherapy. Br J Haematol 83: 674-675, 1993

27) Takahashi Y, Mikami J, Ito $K$, Ueda $M$, Sato $H$, Matsuoka T, Takeda S, Ohkawara S, Tsuchiyama A, Fujisawa Y: [A case of infantile primary cerebellar malignant lymphoma: Report of its interesting CT finding and clinical evaluation]. Shoni No Noshinkei 7: 159-166, 1982 (Jpn, with Eng abstract)

28) Takahashi T, Nakamura K, Sasaki Y: [A case of childhood primary intracranial malignant lymphoma showing meningeal spread]. No Shinkei Geka 13: 327-334, 1985 (Jpn, with Eng abstract)

29) Tooyama $M$, Suzuki K, Yamaki $T$, Naruse $S$, Hirakawa K, Arakawa S, Tozawa M: [Three cases of intracranial malignant lymphoma in children]. Shoni No Noshinkei 5: 405-412, 1980 (Jpn, with Eng abstract)

30) Trapella G, Fabi S, Migliore A, Bianchini E, Cavazzini L: Primary central nervous system lymphoma: A case of long survival. Ital J Neurol Sci 9: 275278,1988

31) Vakili ST, Muller J, Shindai H, Campbell RL: Primary lymphoma of the central nervous system: a clinicopathologic analysis of 26 cases. J Surg Oncol 33: 95-102, 1986

32) Woodman $R$, Skin $K$, Pineo G: Primary nonHodgkin's lymphoma of the brain: A review. Medicine (Baltimore) 64: 425-430, 1985

33) Yasunaga $T$, Takahasi $M$, Uozumi $H$, Takada $C$, Kawano S, Baba Y, Nakamura I, Sonoda H, Matsuoka Y: Radiation therapy of primary malignant lymphoma of the brain. Acta Radiol Oncol 25: 23-28, 1986

34) Yenrudi S, Shuangshoti S: Lymphoma of brain in an infant. J Med Assoc Thai 61: 352-356, 1978

Address reprint requests to: Y. Kai, M.D., Department of Neurosurgery, Kumamoto University Medical School, 1-1-1 Honjo, Kumamoto 860-8556, Japan. 